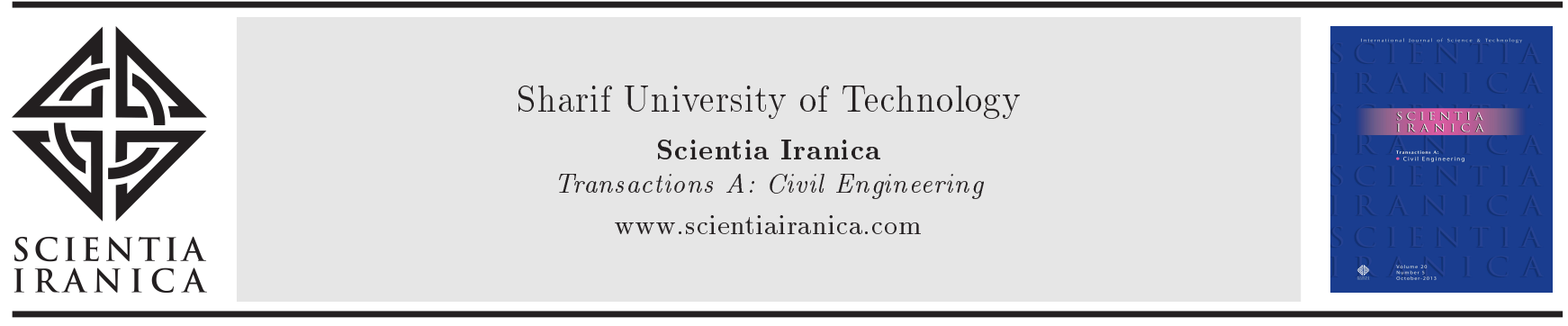

\title{
Application of tire crumbs on mechanical properties of a clayey soil subjected to freeze-thaw cycles
}

\author{
M. Roustaei ${ }^{\mathrm{a}, *}$, M. Ghazavi ${ }^{\mathrm{b}}$ and E. Aliaghaei ${ }^{\mathrm{c}}$ \\ a. Young Researchers and Elite Club, Qazvin Branch, Islamic Azad University, Qazvin, P.O. Box 34185-1416, Iran. \\ b. Department of Civil Engineering, K. N. Toosi University of Technology, Tehran, P.O. Box 15875-4416, Iran. \\ b. Department of Civil Engineering, Imam Khomeini International University, Qazvin, P.O. Box 3414916818, Iran.
}

Received 21 September 2014; received in revised form 7 March 2015; accepted 23 June 2015

\section{KEYWORDS \\ Freeze-thaw cycling; \\ Clay; \\ Tire crumbs; \\ UU triaxial test; \\ Cohesion; \\ Resilient modulus.}

\begin{abstract}
During recent years, processed used tires such as tire shreds, tire chips, tire buffings, and tire crumbs have been applied in order to improve the mechanical properties of soil mixtures. Finding more beneficial ways of using waste tires, this paper assessed the influence of adding tire crumbs to a clayey soil which was affected by freeze-thaw cycles. Freeze-thaw cycling is a weathering process which occurs in cold climates during winter and spring and considerably changes the engineering properties of soils. In the present study, a clayey soil was mixed with six different percentages of tire crumbs $(0,0.5,1,1.5$, $2,2.5)$ and evaluated by triaxial compression tests under three different confining pressures $(30,60,90 \mathrm{kPa})$ after the soil was subjected to $1,3,6$, and 9 cycles of freeze-thaw. It has been found that for the investigated soil, using $2.5 \%$ of tire crumbs decreases the cohesion reduction ratio by about $24 \%$ and the resilient modulus reduction ratio by about $6-42 \%$ during the cycles. Hence, although the addition of tire crumbs does not considerably affect the strength reduction of soil during freeze-thaw cycles, it can reduce the changes of cohesion and resilient modulus of the soil, effectively.

(C) 2016 Sharif University of Technology. All rights reserved.
\end{abstract}

\section{Introduction}

By development in industry and growth in population, a great deal of tire wastes are annually produced all around the world. More than 500 million stoked tires are generated across the United States, 45 million in Europe, and 28 million in Canada [1]. In Iran, about 250 thousand tons of used tires are procreated yearly and this amount will increase to 1.4 million tons in 14 years.

Finding beneficial ways of recycling or reusing this huge amount of waste tires is a matter of great

*. Corresponding author. Tel.: +98 2833665275 ;

Fax: +982188779476

E-mail addresses: mahya_roustaei@qiau.ac.ir (M.

Roustaei); ghazavi_ma@kntu.ac.ir (M. Ghazavi);

Eisa.aliaghaei@qiau.ac.ir (E. Aliaghaei) concern. Large quantities of used tires can be used in geotechnical and geo-environmental applications in different shapes such as crumbs, shreds, buffings, cords, chips, and powder. It has been reported that adding tire particles affect the mechanical properties of soils, significantly. Waste tires are used for reinforcing soft soil in road construction [2-4], to control ground erosion [5], for stabilizing slopes [5,6], as lightweight material for backfilling in retaining structures [2,711], as aggregates in leach beds of landfills [12], as an additive material to asphalt $[3,12,13]$, as sound barriers [14], as limitation for freezing depth [15], as a source for creating heat [7], as a fuel-supplement in coal-fired boilers [16], for vibration isolation [17], as cushioning foams [16], and for low strength but ductile concrete [17-19].

Ghazavi (2004) [20] executed direct shear tests to investigate how shear strength characteristics of sand 
mixed with various percentages of waste garden hose grains were altered. It was shown that adding the rubber grains up to $15 \%$ to the sand can increase the initial friction of the sand friction angle from $37^{\circ}$ to $37.6^{\circ}$ in more compacted mixtures, while in the loose mixtures, friction angle varies from $31.2^{\circ}$ to $35.3^{\circ}$. It was also concluded that addition of $10-$ $20 \%$ rubber to the sand is optimal to obtain the greatest friction angle. In 2005, Ghazavi and Sakhi [21] demonstrated the effect of size of used tire shreds on shear strength parameters of sand reinforced with shredded used tires. They have found that regardless of compaction level and shred contents in the mixtures, for a given width, there is only a certain length that gives the greatest value of friction angle. The absolute greatest value of friction angle about $67^{\circ}$ was obtained by using $50 \%$ shreds with dimensions of $4.38 \mathrm{~cm}$ at unit weight of $16.8 \mathrm{kN} / \mathrm{m}^{3}$. Edinçliler et al (2010) [22] added tire crumb to sand and showed that it caused internal friction to increase from 38.7 to 42.6. Kalkan (2007) [18] showed that the cohesion and internal friction angle values increased by addition of tire rubber, polyethylene, and polypropylene fiber. The UCS (Unconfined Compression Strength) values increased with increase in the tire rubber fiber contents up to $2 \%$ and then decreased. In cold climates, soils are exposed to freeze-thaw cycles, especially on shallow parts. These cycles considerably change the engineering properties of soils. During soil freezing, ice lenses, which tend to form in free spaces between soil aggregates, force them apart and end up the alteration of characteristic structures in micro and macro scales. The effects of freeze thaw cycles on soil behavior was investigated in numerous studies; in the permafrost regions, these cycles influence the soil bearing capacity, significantly. In Canada, it has been found that the embankment constructed on the soil which has never experienced freeze-thaw cycles will damage in just one year due to the loss of bearing capacity [23]. Therefore, newly constructed highway embankments that are left unpaved for a few years may be subjected to possible damages by freeze-thaw cycles [24].

Qi et al. (2006) [25] reviewed the latest efforts which were done to investigate the influence of freezethaw cycles on soil properties. They summarized these influences in two parts: physical properties such as density and hydraulic permeability, and mechanical properties such as ultimate strength, strain-stress behavior, and resilient modulus. As mentioned in this research, loose soils tend to be densified and dense soils become looser after freeze-thaw cycles and both loose and dense soils may attain the same void ratio after a number of cycles [26]. By increasing the large pores that are left after the thaw of ice crystals, permeability will increase [27]. These cycles reduce the ultimate strength of soils. All over-consolidated soils exhibit a peak on the triaxial stress-strain curve that is reduced or may even disappear [28]. Resilient modulus is one of the most important factors in pavement design that significantly reduces by even a small number of freezethaw cycles [29]. In addition, these cycles decrease the undrained shear strength, considerably, which is an important factor in engineering properties of finegrained soils [28].

All the above-mentioned research works deal with unreinforced soil. Along with many applications for soil improvement, there come several widely varied methods. Taking the influence of freeze-thaw cycles on soils into consideration, just a few researchers have contemporarily focused on using additives which can control the effects of these cycles [30].

Yarbesi et al. (2007) [31] stabilized two granular soils by silica fume-lime, fly ash-lime, and red mudcement. Their experimental results show that stabilized samples with the mentioned additive mixtures have high freezing-thawing durability as compared to unstabilized samples. These additive mixtures which have also improved the dynamic behavior of the soil samples can be successfully used as an additive material to enhance the freeze-thaw durability of granular soils for road constructions and earthwork applications.

Kalkan (2009) [32] used a fine grained soil stabilized by adding silica fume which was generated during silicon metal production. The test results show that the stabilized fine-grained soil exhibits high resistance to the freezing and thawing effects as compared to natural fine-grained soil samples. The silica fume decreases the effects of freeze-thaw cycles on unconfined compressive strength and permeability.

Hazirbaba and Gullu (2010) [33] performed CBR tests to investigate the influence of freeze-thaw conditions and also non-freeze-thaw conditions on finegrained soil samples which were treated with the inclusion of geofiber and synthetic fluid in soaked and unsoaked conditions. The results indicate that addition of geofiber together with synthetic fluid is generally successful in providing resistance against freeze-thaw weakening. Liu et al. (2010) [34] conducted dynamic triaxial tests on cement and lime-modified soils with different blend ratios in freeze-thaw cycles. The results show that after repeated freeze-thaw cycles, the modified soils exhibit better performance than those before modification, the cement-modified clay is superior to the lime modified clay, and all soil mechanical properties are visibly improved.

Zaimoglu (2010) [35] investigated the effect of randomly distributed polypropylene fibers on strength and durability behavior of a fine-grained soil subjected to freezing-thawing cycles. He also found that the unconfined compressive strength of specimens subjected to freezing-thawing cycles generally increases with increasing fiber content. In addition, the results 
indicated that the initial stiffness of the stress-strain curves is not affected significantly by the fiber reinforcement in the unconfined compression tests.

Ghazavi and Roustaie (2010) [36] reinforced a kaolinite clay with steel and polypropylene fibers and exposed the soil samples to a maximum of 10 closedsystem freeze-thaw cycles. They found that increasing the number of freeze-thaw cycles results in the decrease in unconfined compressive strength of clay samples by $20-25 \%$. Moreover, the inclusion of fiber in clay samples increases the unconfined compressive strength of soil and decreases the frost heave. Furthermore, the results of the study indicate that addition of $3 \%$ polypropylene fibers results in the increase in unconfined compressive strength of the soil before and after applying freezethaw cycles by $60 \%$ to $160 \%$ and decrease of frost heave by $70 \%$.

Jafari and Esna-ashari (2012) [37] examined the effects of stabilization and fiber reinforcement, simultaneously, on the UCS (unconfined compression strength) of clayey soil subjected to freeze-thaw cycles. The results indicated that for the stabilized specimens, the reinforcement effect of fiber was more than that for unstabilized ones and also, by inclusion of fibers, $4 \%$ lime stabilized specimens showed more strength than the untreated and $8 \%$ lime stabilized specimens.

Having the effect of using waste tires on soil characteristics in mind, the present study investigates the influence of tire crumbs addition on the mechanical behavior of a clayey soil subjected to freeze-thaw cycles. To this end, the strength of a clayey soil reinforced with $0,0.5,1,1.5,2$, and $2.5 \%$ of tire crumbs was evaluated through triaxial test with three different confining pressures $(30,60$, and $90 \mathrm{kPa})$ before and after $0,1,3,6$, and 9 freeze-thaw cycles.

\section{Materials}

In this study, laboratory tests were carried out on a clayey soil classified as CL in the Unified Soil Classification System. It is noted that the effects of freezethaw cycles are more considerable in fine-grain soils than those in sand or gravel [25]. The soil properties are presented in Table 1, and its grain size distribution is shown in Figure 1. Standard Proctor Compaction tests were performed on the soil, and a maximum dry mass density of approximately $1.82 \mathrm{gr} / \mathrm{cm}^{3}$ at Optimum Moisture Content (OMC) of approximately

Table 1. Properties of soil.

\begin{tabular}{cc}
\hline$G_{s}$ & 2.75 \\
Plastic limit & $23 \%$ \\
Liquid limit & $36 \%$ \\
Plastic index & $13 \%$ \\
\hline
\end{tabular}

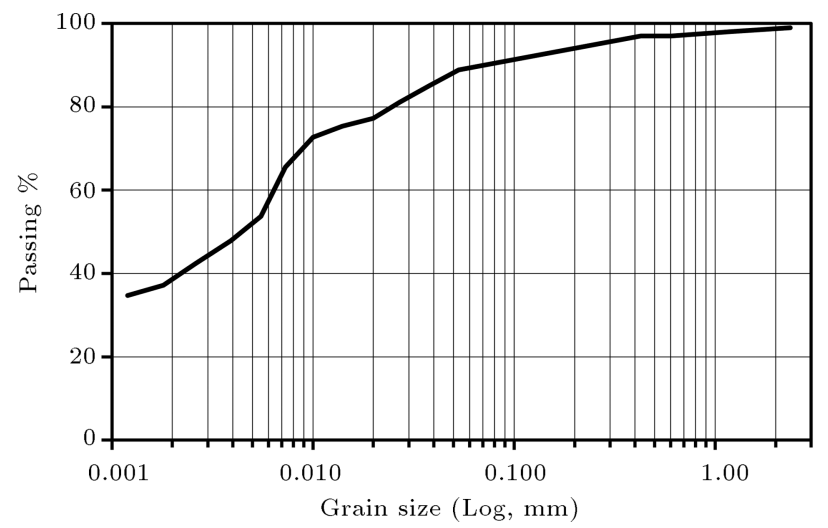

Figure 1. Grain size distribution of clay deposit.

Table 2. Properties of tire crumbs.

\begin{tabular}{cc} 
Unite weight $\left(\mathrm{gr} / \mathrm{cm}^{3}\right)$ & 561 \\
Diameter $(\mathrm{mm})$ & $<0.6$ \\
\hline
\end{tabular}

$14.8 \%$ was obtained. The specimens were mixed with tire crumbs at six percentages $(0 \%, 0.5 \%, 1 \%, 1.5 \%, 2 \%$ and $2.5 \%$ ) by the weight of dry soil. The tire crumbs are produced as waste materials in repairing factory of used tires with the mentioned characteristics in Table 2. After Adding the OMC to the mixture of soil and tire crumbs, they have been put in the plastic bags and sealed for $24 \mathrm{~h}$ to achieve uniform water content within the soil mass.

\section{Testing procedure}

The scope of this investigation is to study the effects of application of waste tire on the strength changes of highly compressible clay compacted at maximum dry density with the optimum moisture content and subjected to 0-9 freeze-thaw cycles. To evaluate the soil changes in these cycles, three main following steps should be taken for each sample.

Sufficient amount of extra samples (approximately thirty percent of the whole) were prepared and tested in order to examine the repeatability of test results.

\subsection{Specimen preparation}

All specimens having $50 \mathrm{~mm}$ diameter and $100 \mathrm{~mm}$ height were prepared with the maximum dry unit weight and optimum water content and were mixed with tire crumbs at six percentages $(0 \%, 0.5 \%, 1 \%$, $1.5 \%, 2 \%$ and $2.5 \%$ ) by the weight of dry soil. For sample preparation, initially, tire crumbs were added to dry soil. Then, the necessary OMC was determined and mixed with the soil. Later on, the mixture was put in the plastic bags and sealed for $24 \mathrm{~h}$ to achieve uniform water content within the soil mass. The moisture content was then checked before sample 
compaction. Due to the elastic behavior of tire crumbs, sample compaction was not possible by kneading or tamping each soil layer. Thereupon, the specimens were compacted by the static uniform load of $450 \mathrm{~kg}$. The amount of the load was determined experimentally to achieve maximum dry mass density and so, by increasing the amount of tire crumbs, the amount of load would have increased consequently.

After removal of each sample from the mold, it was immediately covered with a plastic layer to protect its moisture content.

\subsection{Freeze-thaw cycles}

To prepare the samples for the closed system freezing and thawing cycles, specimens were placed in a digital refrigerator at $-20^{\circ} \mathrm{C}$ for $6 \mathrm{~h}$ and then at $+20^{\circ} \mathrm{C}$ for thawing phase for $6 \mathrm{~h}$. These temperatures had been previously used in some research works [25]. Six hours is a proportional period after which the alteration of specimens' height would become constant. This means that the height increase in freeze phase and the height decrease in thaw phase stop. The cycles were continued up to 9 cycles. This number of cycles was chosen since most soil strength reduction would occur in primary cycles, and after 5-10 cycles, a new equilibrium condition would become predominant on samples $[30,36]$.

\subsection{Strength testing}

Strength parameters of soil were measured in Unconsolidated Undrained (UU) triaxial compression tests after $0,1,3,6$, and 9 cycles keeping the strain rate constant at $1 \mathrm{~mm}$ per minute throughout the testing program in accordance with ASTM D2850-03a [38].

To simulate the real conditions of freeze and thaw cycles which occur practically on shallow depths of soil, three different confining pressures of 30,60 , and $90 \mathrm{kPa}$ were selected for triaxial tests $[30,6]$. The results have been shown through stress-strain response of samples and changes of resilient modulus.

Resilient modulus is a fundamental material property used to characterize unbound pavement materials. It is a measure of material stiffness and provides a mean to analyze stiffness of materials under different circumstances, such as moisture content, density, and stress level. It is also a required input parameter for mechanistic-empirical pavement design method.

The resilient modulus is defined as a ratio of the deviator stress increment at $1 \%$ axial strain to the axial strain increment, which can be expressed by:

$$
E=\frac{\Delta \sigma}{\Delta \varepsilon}=\frac{\sigma_{1.0 \%}-\sigma_{0}}{\varepsilon_{1.0 \%}-\varepsilon_{0}}
$$

where $\Delta \sigma$ is the increment of deviator stress, $\Delta \varepsilon$ is the increment of axial strain, $\sigma_{1.0} \%$ is the deviator stress corresponding to the axial strain of $1.0 \%\left(\varepsilon_{1.0 \%}\right)$, and $\sigma_{0}$ and $\varepsilon_{0}$ are the initial stress and strain, respectively [39].

Lee et al. (1995) [40] investigated the resilient properties of cohesive soils and found that cohesive soils with resilient moduli lower than $55 \mathrm{kPa}$ would exhibit negligible freeze-thaw effects. In contrast, soils with resilient moduli higher than $103 \mathrm{kPa}$ would exhibit a decrease by over $50 \%$ in this parameter due to freezethaw.

Wang et al. (2007) [39] also reported that magnitude of the resilient modulus decreases by $18-27 \%$ of that of unfrozen soil depending on the confining pressure in triaxial compression tests.

\section{Results}

In order to find out the detailed effects of using tire in clay samples during the freeze-thaw cycles, triaxial compression tests have been conducted on unfrozen and thawed tire-clay mixtures with six different tire percentages $(0,0.5,1,1.5,2,2.5)$ under three different confining pressures $(30,60,90 \mathrm{kPa})$ after the soil was subjected to $1,3,6$, and 9 cycles of freeze-thaw.

The variations of stress-strain response of samples are named NC-0T for pure samples under $N$ freezethaw cycles and NC-XT for reinforced samples with $X \%$ of polypropylene fibers subjected to $N$ freeze-thaw cycles.

\subsection{Effect of using tire on mechanical behavior of clay before freeze-thaw cycles}

UU triaxial test was used in order to measure the strength of soil according to the methodology described in ASTM D2850-03a and to investigate the changes of soil mechanical features after freeze-thaw cycles. But in the beginning, it is recommended to explore the changes in clay properties according to tire crumbs addition prior to any cycles. Figure 2 shows the stressstrain curves of pure samples and clay-tire mixtures before freeze thaw cycles in three different confining pressures. This figure indicates that adding tire crumbs to clayey soil has negligible effect on increasing the strength of soil. The strength of clayey soil considerably depends on cohesion. Since the cohesion between tire and soil particles is insignificant, adding the tire crumbs to clayey soil may destroy the cohesion between clayey particles.

Figure 2 also shows that by increasing the confining pressure, the effect of tire is more visible. This fact is also obvious from Figure 3 in which the failure strength of soil samples is indicated by considering the peak of stress-strain curves as failure strength. Since confining pressure is a factor that increases the interaction between soil and tire particles, adding tire crumbs is more effective in high confining pressures which occurs in deeper parts of ground. 

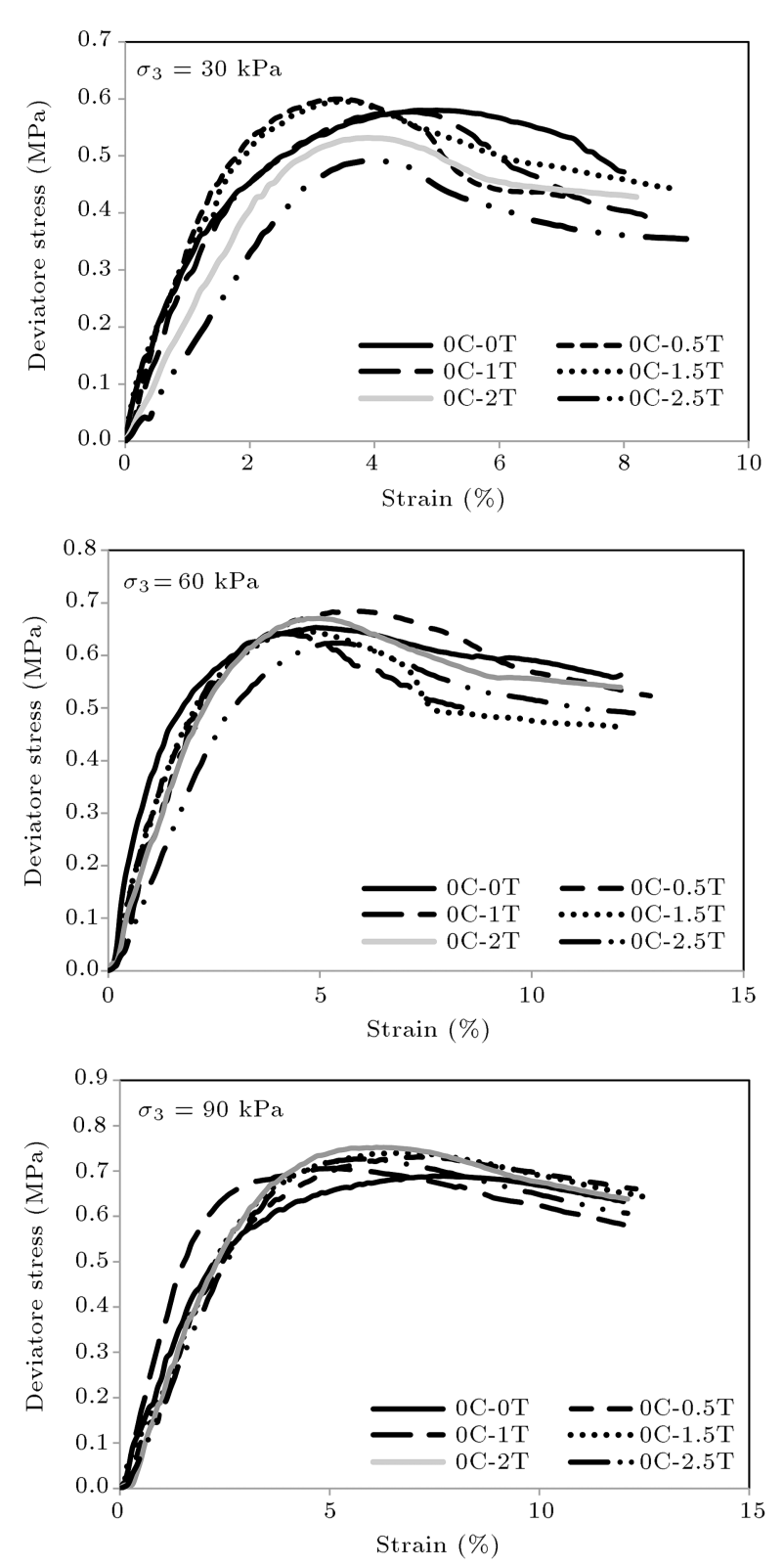

Figure 2. Stress-strain variation of pure samples and tire-clay mixtures before freeze-thaw cycles under three different confining pressures.

According to these figures, in comparison with the pure samples, the ultimate strength of tire-clay mixtures at 1 and $2 \%$ tire contents under confining pressure of $90 \mathrm{kPa}$ increased from 0.779 to 0.796 and $0.842 \mathrm{MPa}$, respectively. It can be concluded that inclusion of $0.5-2 \%$ tire crumbs in clayey soil results in increasing the failure strength to about $2.5-8 \%$.

It can also be seen that as the tire particles are used in crumb shapes, they have no tension operation; so, by increasing the amount of tire particles, the behavior of clayey soil tends to vary from strainhardening type to strain- softening type.

As previously mentioned, cohesion is one of the most important characteristics of soil which consider-

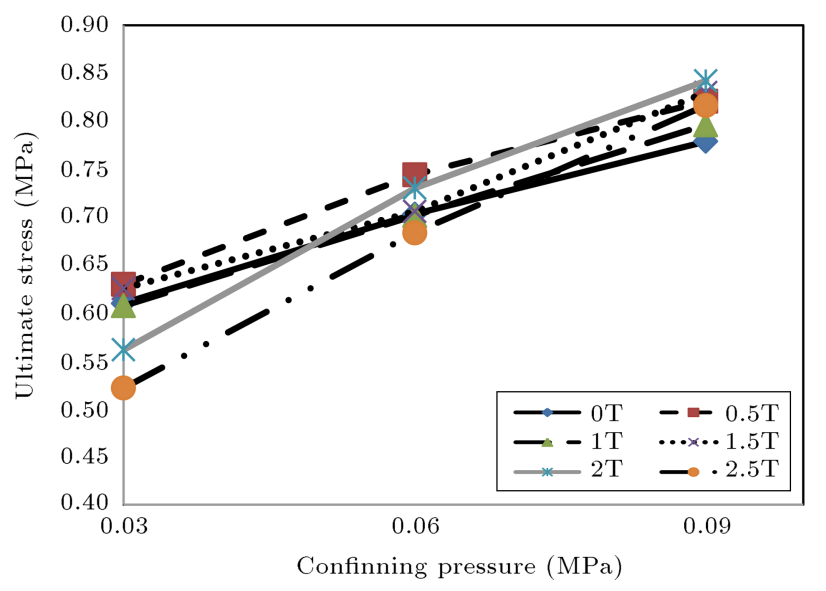

Figure 3. Variation of ultimate strength of pure samples and tire-clay mixtures versus confining pressures.

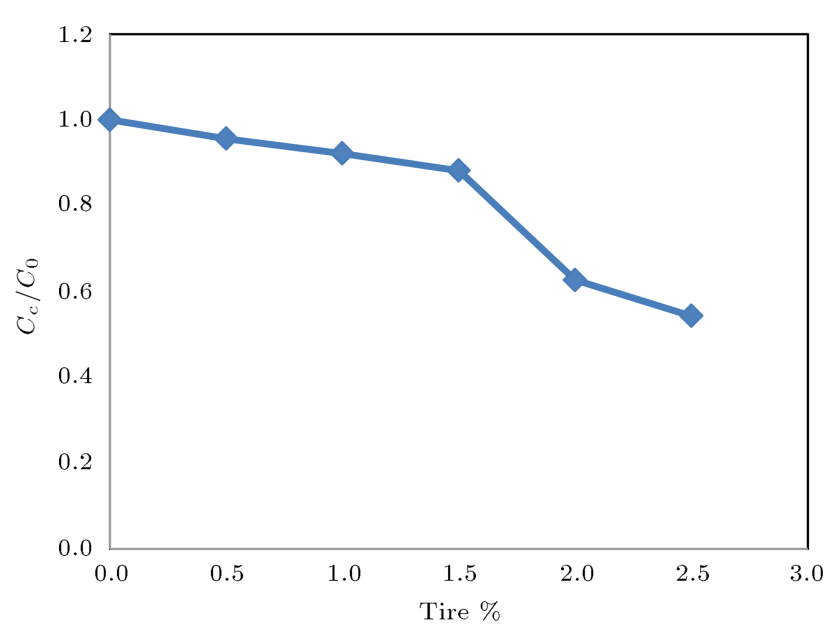

Figure 4. Variation of cohesion of clay after the addition of tire crumbs.

ably affects the strength of cohesive soils such as clay. The influence of the adding tire crumbs on cohesion of clay samples is illustrated in Figure 4. In this figure, $C_{c}$ is the cohesion of tire-clay mixtures and $C_{0}$ is the cohesion of pure clayey samples. As seen, the soil cohesion decreases by about $60 \%$ by adding tire crumbs. This phenomenon is a result of scanty cohesion between fibers and soil particles. So, the cohesion reduction can be visible by increasing the tire content in the soil.

\subsection{Effect of freeze-thaw cycles}

The strength features of pure samples and clay-tire mixtures were measured in UU triaxial compression tests after $0,1,3,6$, and 9 cycles. The results are described in the following sections.

\subsubsection{Failure strength}

The effect of adding tire crumbs on increasing the ultimate strength of clayey soil is not the aim of this study, but the changes in behaviors of pure soil and tireclay mixtures during the freeze thaw cycles are more 

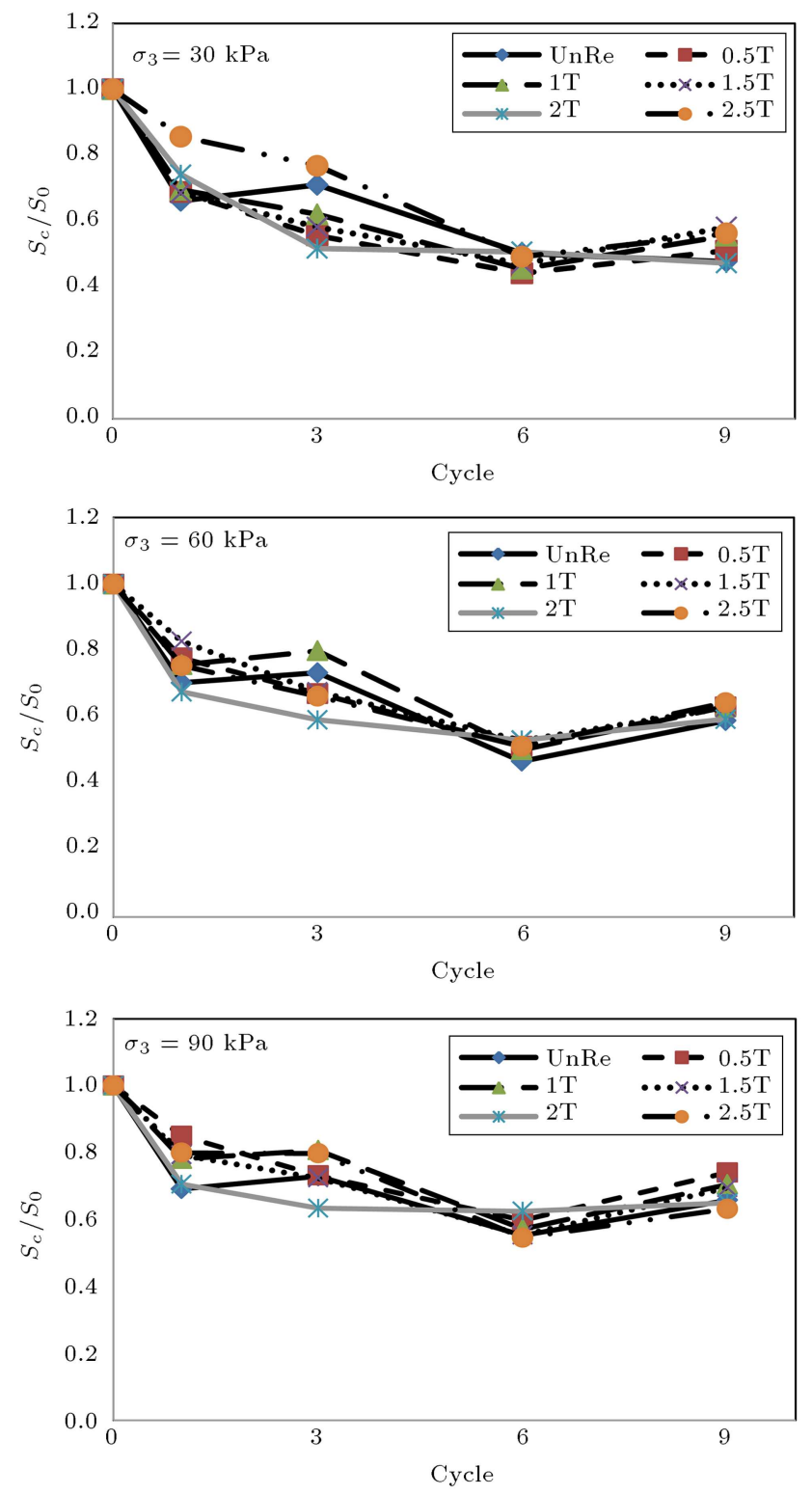

Figure 5. Variation of strength ratio of pure samples and tire-clay mixtures versus freeze-thaw cycles under confining pressures of 30,60 , and $90 \mathrm{kPa}$.

noteworthy and should be investigated. Figure 5 shows the triaxial strength ratio of pure samples and claytire mixtures versus the number of freeze-thaw cycles for various confining pressures. The ratio is defined as the strength of a pure sample or clay-tire mixture at a given cycle divided by that of the same sample which is not subjected to freeze-thaw cycles. The strength values are denoted by $S_{c}$ and $S_{0}$, respectively. Figure 5 indicates the four following facts:

1. By increasing the number of freeze-thaw cycles, the strength of both pure samples and clay-tire mixtures decreases. Separation of clay aggregates which is caused by ice lenses, made up of soil pure water at temperatures just below $0^{\circ} \mathrm{C}$, disrupts the interlocking and cohesion of soil grains and decreases strength. The strength reductions for pure and mixed soils subjected to freeze-thaw cycles have also been observed in previous studies $[28,30,36]$;

2. By increasing the confining pressure, the strength reduction decreases. Therefore, freeze-thaw cycles are more destructive on surface of the ground which is in contact with structure foundations or road pavement. Soil particle rearrangement which is caused by higher confining pressure will close the cracks and fissures produced by freeze-thaw process and enhances soil strength [39];

3. Strength reduction of clay-tire mixtures, especially in the first three cycles, is minor in comparison with pure samples. As it is observed in previous studies that the first cycles have the greatest influence on soil strength, tire crumbs are appropriate additives for reducing these changes;

4. As a whole, the strength reduction ratio of soil samples decreases by about $8 \%$ during 9 cycles just by adding tire crumbs. This fact can be investigated in detail by discovering the changes in shear strength parameters of soil during the cycles, which will be presented in the following sections.

\subsubsection{Resilient modulus}

The resilient modulus of pure and mixed samples subjected to each freeze-thaw cycle can be calculated by Eq. (1), as shown in Figure 6. The resilient modulus values are soil samples after and before the cycles are denoted by Ec and E0, respectively. The figure shows that by increasing the number of cycles, the resilient moduli of both pure and mixed samples decrease. This figure also indicates that the decrease magnitude of resilient modulus for pure samples is more obvious in first cycles, but in tire-clay mixtures, especially under confining pressure of $90 \mathrm{kPa}$, the reduction amount of resilient modulus will obviously decrease.

When the number of freeze-thaw cycles exceeds seven, the resilient modulus will reach a certain value and remains constant upon applying further freezethaw cycles. This phenomenon shows a new equilibrium condition which becomes predominant in the clayey soil after 6-7 cycles as most of the changes occur between the 1 st to the 7 th cycles $[25,36]$.

The minimum amounts of resilient modulus reduction under confining pressure of $90 \mathrm{kPa}$ are shown in Table 3. These numbers demonstrate that by adding $0.5-2 \%$ of tire crumbs to clayey soil, the resilient modulus reduction will decrease by about $6-42 \%$.

\subsubsection{Cohesion}

Cohesion is an important factor for evaluating the shear strength of fine-grained soils. This parameter reflects the synthesis action of all kinds of physicalchemical forces between particles, such as Coulomb 

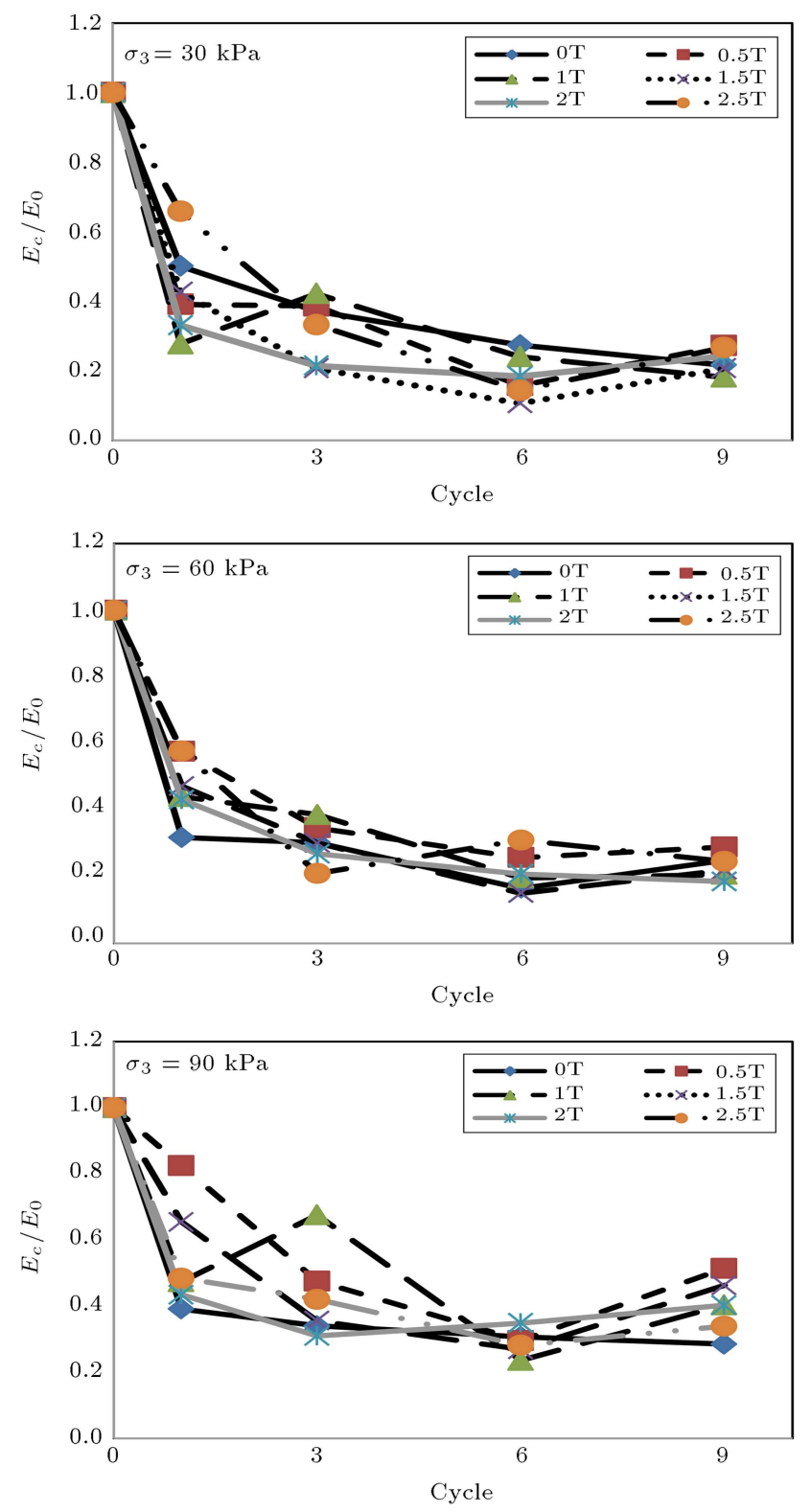

Figure 6. Variation of resilient modulus of pure samples and tire-clay mixtures versus freeze-thaw cycles under confining pressures of 30,60 , and $90 \mathrm{kPa}$.

force, Vander Waals forces and the ions of adjacent particles, bonding action, and so on.

In order to investigate the effect of freeze-thaw action on the shear strength the clayey soil, which is chosen in this study, the effect of freeze-thaw cycle on cohesive force will be observed. The influence of the number of freeze-thaw cycles on the cohesion of pure and mixed samples is illustrated in Figure 7 . The cohesion values are soil samples after and before the cycles denoted by $C_{c}$ and $C_{0}$, respectively. As seen, the soil cohesion decreases with increasing the number of freeze-thaw cycles, although there are some points in which the soil cohesion increases. Drawing the trend lines of cohesion curves in Figure 8, it is obvious that
Table 3. Minimum reduction amounts of resilient modulus of tire-clay mixtures under confining pressure of $90 \mathrm{kPa}$.

\begin{tabular}{cccc}
\hline $\begin{array}{c}\text { Tire } \\
\text { crumbs } \\
(\%)\end{array}$ & Cycle & $\begin{array}{c}\text { E reduction } \\
\text { amount (\%) } \\
\text { of tire-clay } \\
\text { mixtures }\end{array}$ & $\begin{array}{c}\text { E reduction } \\
\text { amount (\%) } \\
\text { of pure } \\
\text { samples }\end{array}$ \\
\hline 0.5 & 1 & 18 & 60 \\
1 & 3 & 33 & 66 \\
2 & 6 & 65 & 70 \\
0.5 & 9 & 49 & 55 \\
\hline
\end{tabular}

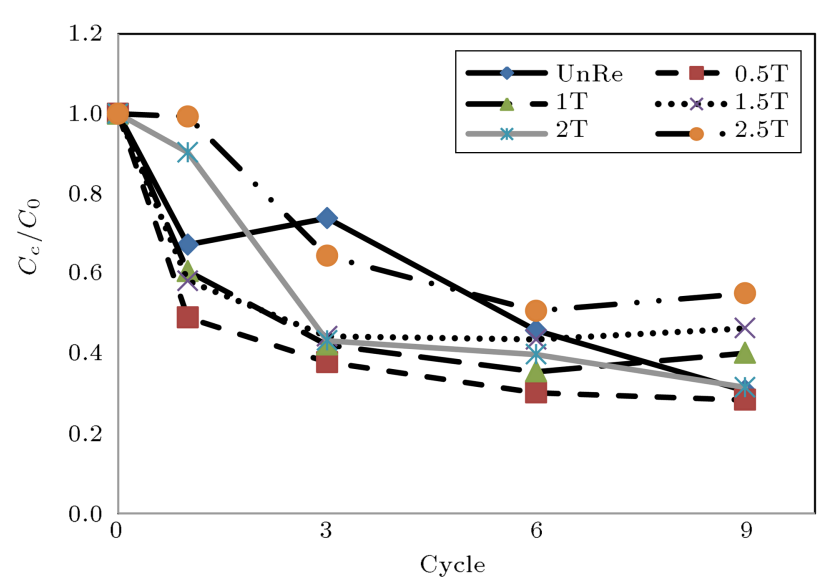

Figure 7. Variation of soil cohesion of pure samples and tire-clay mixtures versus freeze-thaw cycles.

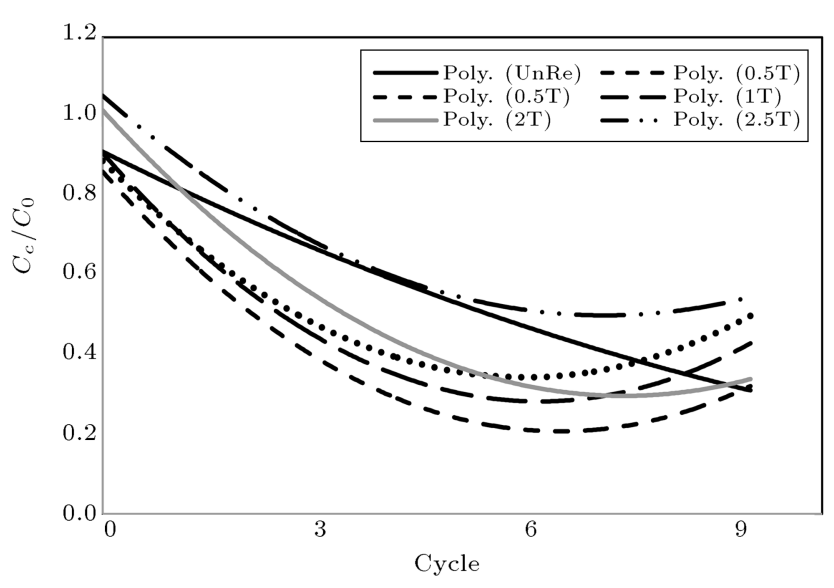

Figure 8. Polynomial trend lines of cohesion changes of pure samples and tire-clay mixtures during freeze-thaw cycles.

cohesion reduction of pure samples during freeze-thaw cycles is more than tire-clay mixtures. Furthermore, the cohesion reduction trend of pure samples continues up to the 9th cycle; however, the changes in the cohesion parameter of tire-clay mixture are more in the first three cycles and less in the 6th and 9th. Adding $2.5 \%$ of tire crumbs to clayey soil decreases the cohesion reduction ratio by about $24 \%$. In addition, the trends 


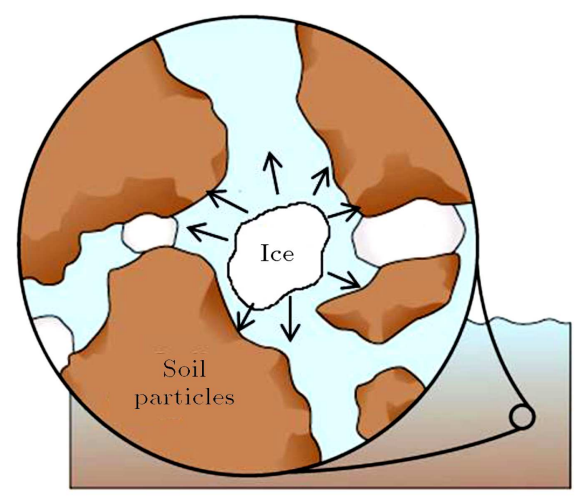

Pure samples

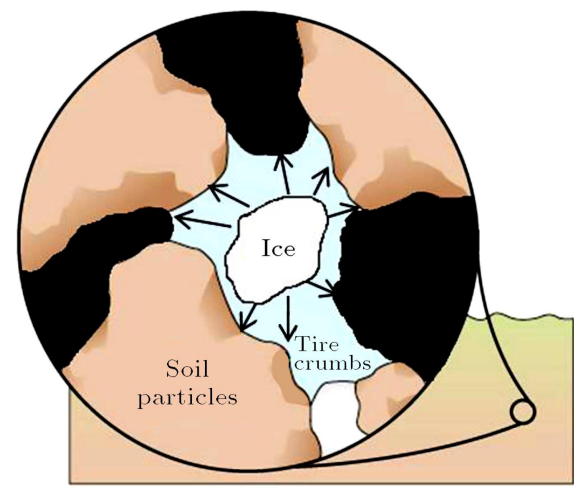

Tire-clay mixtures

Figure 9. Section of pure samples and tire-clay mixtures particles in contact with tire crumbs in the freezing phase in microscopic scale.

of tire-clay mixtures could show a new equilibrium condition that would become predominant in samples after the 6th cycle.

The magnitude of cohesion is frequently influenced by the space between particles and bonding force caused by bonding material [39]. Cohesion reduction suggests that voids between clay particles may increase due to the formation of ice lenses thus increasing the volume. By adding the tire crumbs to soil samples, a section of tire-clay mixtures in microscopic scale can be considered as shown in Figure 9. At temperatures just below $0^{\circ} \mathrm{C}$, pore water transforms into ice and the volume of ice lenses increases up to 9 times, applying a considerable stress on soil aggregates, making them to move. So, the spaces between soil particles increase and these increased spaces remain even after thawing, resulting in cohesion reduction. In tire-clay mixtures, some parts of these stresses are applied on tire crumbs, and because the tire crumbs have elastic characteristics, the stresses will be absorbed by them. After thawing, the absorbed stresses will be released, so the tire particles will move to their initial positions. In fact, the soil particles which are surrounded by tire crumbs may move less than the others. As a result, cohesion reduction during the cycles in tire-clay mixture will be less than that in the pure samples.

\section{Conclusion}

Laboratory tests and experimental investigations were conducted to probe the potential use of a lightweight waste material, such as tire-crumbs, to reduce the changes of a clayey soil during freeze-thaw cycles. The results are as follow:

- The strength of clayey soil is fully dependent on cohesion. Since the cohesion between tire crumbs and clay particles is scant, addition of tire crumbs to clayey soil has negligible effect on the increase of cohesion in soil. Strength reduction of clayey sam- ples due to increasing the tire crumbs percentages is observed during this investigation, particularly in low confining pressures;

- In consequence of insignificant cohesion between tire crumbs and clay particles, the cohesion reduction can be visible by increasing the tire content in the soil.

- Confining pressure is a factor that increases the interaction between soil and tire particles. So, adding tire crumbs is more effective in high confining pressures. Expectedly, inclusion of $0.5-2 \%$ tire crumbs in clayey soil results in increase in the failure strength by about 2.5-8\%;

- By adding tire crumbs, the behavior of clayey soil tends to vary from strain-hardening to strainsoftening type;

- By increasing the number of freeze-thaw cycles, the strength of both pure samples and clay-tire mixtures decreases;

- Freeze-thaw cycles are more destructive on the surface of the ground which is in contact with structure foundations or road pavement, since by increasing the confining pressure, the strength reduction decreases;

- Strength reduction of clay-tire mixtures, especially in the first three cycles, is minor in comparison with pure samples. Also, strength reduction ratio of soil samples decreases by about $8 \%$ during 9 cycles just by adding tire crumbs;

- By increasing the number of cycles, the resilient moduli of both pure and mixed samples decrease. The decrease magnitude of resilient modulus for pure samples is more obvious in the first cycles. However, in tire-clay mixtures, especially under confining pressure of $90 \mathrm{kPa}$, the reduction amount of resilient modulus obviously declines. Addition of 0.5-2\% tire crumbs to clayey soil reduces the resilient modulus reduction by about $6-42 \%$; 
- Tire particles absorb the stresses due to the increase in volume of ice crystals; hence, cohesion reduction during the cycles in tire-clay mixture will be less than that in the pure samples. Adding $2.5 \%$ of tire crumbs to clayey soil reduces the cohesion reduction ratio by about $24 \%$ during the cycles.

Findings of this study show that addition of tire crumbs is effective in reducing the influences of freezethaw cycles exclusively in high confining pressures and in the first cycles. In addition, the optimum percentage of tire is between $1-2 \%$ as in this range, the changes in mechanical features of soil decrease during freeze-thaw cycles.

Based on the above-mentioned statements, it is recommended to use $1-2 \%$ of tire crumbs in cold climates where soil is exposed to less freeze-thaw cycles. These additives should be used in deeper parts of soil where the confining pressure is at least $90 \mathrm{kPa}$ (about 5 meters). As a result, the maintenance costs of soil structures or pavements during cold months will fall.

\section{Acknowledgment}

The authors would like to thank the Qazvin branch of Azad University for financial supports for this research.

\section{References}

1. Dickson, T.H. and Dwyer, D.F. and Humphrey, D.N. "Prototypes tire-shred embankment construction", Transportation Research Record 1755, TRR, National Research Council, Washington, DC, pp. 160167 (2001).

2. Bosscher, P.J., Edill, T.B. and Kuraoke, S. "Design of highway embankments using tire chips", Journal of Geotechnical and Geoenviromental Engineering, ASCE, 123(4), pp. 297-304 (1997).

3. Heimdahl, C. and Druscher, A. "Elastic anisotropy of tire shreds", Journal of Geotechnical and Geoenviromental Engineering, ASCE, 125(5), pp. 383-389 (1999).

4. Nightingale, D.E.B. and Green, W.P. "An unsolved riddle: tire chips, two roadbeds, and spontaneous reactions", In: M.A. Wasemiller and K.B. Hoddinott (Eds.), Testing Soil Mixed with Waste or Recycled Materials, ASTM STP 1275, pp. 265-285 (1997).

5. Poh, P.S.H. and Broms, B.B. "Slope stabilization using old rubber tires and geotextiles", Journal of Performance of Constructed Facilities, 9(1), pp. 76-80 (1995).

6. Garga, V.K. and O'Shaughnessy, V. "Tire-reinforced earthfill. Part 2: Pull-out behavior and reinforced slope design", Canadian Geotechnical Journal, 37, pp. 97116 (2000a).
7. Lee, J.H., Salgado, R., Bernal, A. and Lovell, C.W. "Shredded tires and rubber-sand as lightweight backfill", Journal of Geotechnical and Geoenviromental Engineering, ASCE, 125(2), pp. 132-141 (1999).

8. Basheer, I.A. and Najjar, Y.M. "Rubber tires and geotextiles", Journal of Performance of Constructed Facilities, 10(1), pp. 40-44 (1996).

9. Sumanarathna, I.H.D., Mallawarctchie, D.P. and Kulathilaka, S.A.S. "Stabilization of slopes by anchored type retaining structures", In: Proceedings of 14 th International Conference of Soil Mechanics and Foundation Engineering, New Delhi, India, pp. 1261-1264 (1997).

10. Garga, V.K. and O'Shaughnessy, V. "Tire-reinforced earthfill. Part 1: Construction of a test fill, performance, and retaining wall design", Canadian Geotechnical Journal, 37, pp. 75-96 (2000b).

11. Allman, M.A. and Simundic, G. "Testing of a retaining wall constructed of waste tires", Proceedings of the Third International Congress on Environmental Geotechnics, Lisbon, Portugal E1 (1998).

12. Foose, J., Benson, H. and Bosscher, J. "Sand reinforced with shredded waste tires", Journal of Geotechnical Engineering, ASCE, 122(9), pp. 760-767 (1996).

13. Tuncan, M., Cetin, A., Tuncan, A. and Koyuncu, H. "Assessment of waste tires and plastic on asphalt concrete pavement mixtures", In: Proceedings of Third International Congress on Environmental Geotechnics, Lisbon, Portugal, 2, pp. 667-672 (1998).

14. Hall, T. "Reuse of shredded tire material for leachate collection system", In: Proc. 14th. Annu. Conf. Dept. of Engrg. Prof., Devel, Uni. of Wisconsin, Madison, Wis., pp. 367-376 (1991).

15. Humphrey, D., Sandford, T., Cribbs, M. and Manison, W. "Shear strength and compressibility of tire chips for use as retaining wall backfill", Transportation Research Record, No. 1422, Transportation Research Board, Washington, DC, pp. 29-35 (1993).

16. Ahmed, I. and Lovell, C. "Use of rubber tires in highway construction", Utilization of Waste Materials in Civil Engineering Construction, ASCE, New York, N.Y., pp. 166-181 (1993).

17. Eldin, N.N. and Senouci, A.B. "Rubber-tire particles as concrete aggregate", Journal of Materials in Civil Engineering, 5(4), pp. 478-496 (1993).

18. Kalkan, E. "Modification of clayey soils using scrap tire rubber and synthetic fibers", Applied Clay Science, 38, pp. 23-32 (2007).

19. Roustaie, M. and Ghazavi, M. "Strength characteristics of clay mixtures with waste materials in freezethaw cycles", Journal of Structural Engineering and Geotechnics, 1(2), pp. 57-62 (2011).

20. Ghazavi, M. "Shear strength characteristics of sandmixed granular rubber", Geotechnical and Geological Engineering, 22, pp. 401-416 (2004). 
21. Ghazavi, M. and Sakhi, M.A. "Influence of optimized tire shreds on shear strength parameters of sand", International Journal of Geotechnics, 5(1), pp. 58-65 (2005).

22. Edinçliler, A., Baykal, G. and Saygýlý, A. "Influence of different processing techniques on the mechanical properties of used tires in embankment construction", Waste Management, 30, pp. 1073-1080 (2010).

23. Leroueil, S., Tardif, J., Roy, M. and Konrad, J.M. "Effects of frost on the mechanical behavior of Champlain Sea clays", Canadian Geotechnical Journal, 28(5), pp. 690-697 (1991).

24. Eigenbrod, K.D. "Effects of cyclic freezing and thawing on volume changes and permeabilities of soft finegrained soils", Canadian Geotechnical Journal, 33, pp. 529- 537 (1996).

25. Qi, J., Vermeer, P.A. and Cheng, G. "A review of the influence of freeze-thaw cycles on soil geotechnical properties", Permafrost and Periglac. Process., 17, pp. 245-252 (2006).

26. Konrad, J.M. "Physical processes during freeze-thaw cycles in clayey silts", Cold Regions Science and Technology, 16, pp. 291-303 (1989).

27. Chamberlain, E.J., Iskander, I. and Hunsiker, S.E. "Effect of freeze-thaw on the permeability and macrostructure of soils", Proceedings of the International Symposium on Frozen Soil Impacts on Agriculture, Range, and Forest Lands. Cold Regions Research and Engineering Laboratory, Hanover, New Hampshire, U.S.A. Special Report, 90-1, pp. 145-155 (1990).

28. Graham, J. and Au, V.C.S. "Effects of freeze-thaw and softening on a natural clay at low stresses", Canadian Geotechnical Journal, 22(1), pp. 69-78 (1985).

29. Simonsen, E. and Isacsson, U. "Soil behavior during freezing and thawing using variable and constant confining pressure triaxial tests", Canadian Geotechnical Journal, 38, pp. 863-875 (2001).

30. Ghazavi, M. and Roustaie, M. "Freeze-thaw performance of clayey soil reinforced with geotextile layer", Cold Regions Science and Technology, 89, pp. 22-29 (2013).

31. Yarbesi, N., Kalkan, E. and Akbulut, S. "Modification of the geotechnical properties, as influenced by freezethaw, of granular soils with waste additives", Cold Regions Science and Technology, 48, pp. 44-54 (2007).

32. Kalkan, E. "Effects of silica fume on the geotechnical properties of fine-grained soils exposed to freeze and thaw", Cold Regions Science and Technology, 58, pp. 130-135 (2009).

33. Hazirbaba, K. and Gullu, H. "California Bearing Ratio improvement and freeze-thaw performance of finegrained soils treated with geofiber and synthetic fluid", Cold Regions Science and Technology, 63, pp. 50-60 (2010).

34. Liu, J., Wang, T. and Tian, Y. "Experimental study of the dynamic properties of cement- and lime-modified clay soils subjected to freeze-thaw cycles", Cold Regions Science and Technology, 61, pp. 29-33 (2010).

35. Zaimoglu, A.S. "Freezing-thawing behavior of finegrained soils reinforced with polypropylene fibers", Cold Regions Science and Technology, 60, pp. 63-65 (2010).

36. Ghazavi, M. and Roustaie, M. "The influence of freezethaw cycles on the unconfined compressive strength of fiber-reinforced clay", Cold Regions Science and Technology, 61, pp. 125-131 (2010).

37. Jafari, M. and Esna-ashari, M. "Effect of waste tire cord reinforcement on unconfined compressive strength of lime stabilized clayey soil under freeze-thaw condition", Cold Regions Science and Technology, 82, pp. 21-29 (2012).

38. ASTM, Standard Test Method for UnconsolidatedUndrained Triaxial Compression Test on Cohesive Soils, American Society for Testing and Materials, Annual Book of ASTM Standards, ASTM Manual ASTM D2850-03a (2007).

39. Wang, D., Ma, W., Niu, Y.H., Chang, X. and Wen, Z. "Effects of cyclic freezing and thawing on mechanical properties of Qinghai-Tibet clay", State Key Laboratory of Frozen Soil Engineering, Cold and Arid Regions Environmental and Engineering Research Institute, Cold Regions Science and Technology, 48, pp. 34-43 (2007).

40. Lee, W., Bohra, N.C., Altschaeffl, A.G. and White, T.D. "Resilient modulus of cohesive soils and the effect of freeze-thaw", Canadian Geotechnical Journal, 32, pp. 559-568 (1995).

\section{Biographies}

Mahya Roustaei received her BSc degree in Civil Engineering from University of Science and Culture, Tehran, in 2006 and MSc and PhD degrees in Geotechnical Engineering in 2008 and 2013 from Khaje Nasir Toosi University of Technology (K.N.T.U), respectively. In 2010, she joined the Department of Civil Engineering at Qazvin Branch of Islamic Azad University, QIAU, where she is currently an Assistant Professor. She has also been selected as the director of Construction and Concrete Research Center (CCRC) of QIAU in 2014. Her research interests include effects of freeze-thaw cycles on static and dynamic properties of soil in pure and reinforced samples, soil reinforcement, and waste management.

Mahmoud Ghazavi Received his BSc and MSc degrees in Civil Engineering in 1986 from Tehran University, Department of Civil Engineering. He is currently a professor in Geotechnical Engineering in the Faculty of Civil Engineering at Khaje Nasir Toosi University of Technology (K.N.T.U). He has also worked as a Professional Engineer in more than 100 projects. He has 
published more than 200 research papers in journals and conferences. His research interests mainly include foundation engineering and ground improvement. He has already supervised about 60 graduate students, including $\mathrm{PhD}$ students.

Eisa Aliaghaei received the BSc degree in Civil Engineering in 2006 from Qazvin branch of Islamic Azad University (QIAU), and MSc degree in Geotechnical
Engineering in 2014 from Imam Khomeini International University, Qazvin. He worked as a research assistant at QIAU research laboratories from 2011 for two years. He is now working as the geotechnical expert in Construction and Concrete Research Center (CCRC) of QIAU. His research interests include soil reinforcement, effects of freeze-thaw cycles on soil, using waste materials as reinforcing elements of soil, and the dynamic properties of soil. 